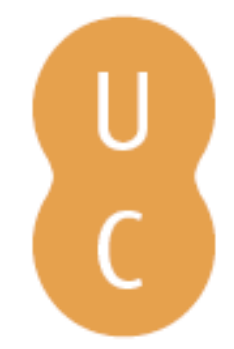

\title{
pommalina
}

\section{Dinâmica civilizacional e diversidade gastronómica: algumas aportações do Livro II das Enarrationes de Amato Lusitano}

\author{
Autor(es): $\quad$ Reis, Telmo Corujo dos \\ Publicado por: Imprensa da Universidade de Coimbra; Annablume \\ URL \\ persistente: URI:http://hdl.handle.net/10316.2/39659 \\ DOI: $\quad$ DOI:https://doi.org/10.14195/978-989-26-1191-4_30 \\ Accessed : $\quad$ 26-Apr-2023 05:41:06
}

A navegação consulta e descarregamento dos títulos inseridos nas Bibliotecas Digitais UC Digitalis, UC Pombalina e UC Impactum, pressupõem a aceitação plena e sem reservas dos Termos e Condições de Uso destas Bibliotecas Digitais, disponíveis em https://digitalis.uc.pt/pt-pt/termos.

Conforme exposto nos referidos Termos e Condições de Uso, o descarregamento de títulos de acesso restrito requer uma licença válida de autorização devendo o utilizador aceder ao(s) documento(s) a partir de um endereço de IP da instituição detentora da supramencionada licença.

Ao utilizador é apenas permitido o descarregamento para uso pessoal, pelo que o emprego do(s) título(s) descarregado(s) para outro fim, designadamente comercial, carece de autorização do respetivo autor ou editor da obra.

Na medida em que todas as obras da UC Digitalis se encontram protegidas pelo Código do Direito de Autor e Direitos Conexos e demais legislação aplicável, toda a cópia, parcial ou total, deste documento, nos casos em que é legalmente admitida, deverá conter ou fazer-se acompanhar por este aviso.

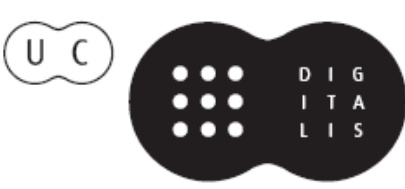




\title{
DiNÂMICA CIVILIZACIONAL E DIVERSIDADE GASTRONÓMICA - ALGUMAS APORTAÇÕES Do LiVRo II DAs ENARRATIONES DE Amato LuSitano
} Civilizational dynamics and gastronomic diversity - some contributions from Book II of the Enarrationes by Amatus Lusitanus

\author{
Telmo Corujo dos Reis \\ Universidade da Madeira \\ Centro de Estudos Clássicos da Universidade de Lisboa \\ treis@uma.pt
}

Resumo: Ao longo das eras, o espaço geográfico que actualmente corresponde a Portugal viu-se submetido à influência de várias civilizações. As mais marcantes terão sido, nos séculos que enquadram o início da era cristã, a civilização romana e, nos que emolduram a génese de Portugal, a civilização islâmica. Depois seria a vez de Portugal imprimir, por via dos Descobrimentos, a sua marca na identidade da civilização ocidental.

Cada um destes três momentos constituiu um espaço privilegiado para o intercâmbio de bens culturais, entre os quais se contam, naturalmente, os produtos alimentares que, em geral, não mais desapareceram dos hábitos gastronómicos das populações. O património alimentar do Ocidente peninsular aparece, assim, marcado por uma progressiva diversidade gastronómica que sobrevive, incólume, à passagem do tempo. Ao comentar a obra de Dioscórides de Anazarbo, o médico português Amato Lusitano consigna algumas aportações atinentes a esta questão. O presente ensaio propõe-se explorá-la, ilustrando-a com exemplos concretos tomados das entradas finais do Livro II das In Dioscoridis Anazarbei De Medica Materia Libros Quinque Enarrationes Eruditissimae, impressas em 1553, nas quais se guarda até uma referência à novidade dos produtos que então chegavam a Lisboa, capital do reino, trazidos da longínqua Ilha da Madeira.

Palavras-chave: Amato Lusitano; património alimentar; diversidade gastronómica; civilização romana; Descobrimentos; Ilha da Madeira.

Aвstract: Throughout the ages, the geographic space that currently corresponds to Portugal found itself under the influence of various civilizations. The most significant ones have been, in the centuries incorporating the beginning of the Christian era, the Roman civilization, and in the ones that frame the genesis of Portugal, the Islamic civilization. Then it would be the turn of Portugal to leave its mark, through the Discoveries, in the identity of the Western civilization.

Each of these three moments provided a forum for the exchange of cultural goods, among which there are, of course, food products, that, in general, did not disappear from the gastronomic habits of the populations. Food heritage of the West of the 
Iberian Peninsula is therefore characterized by a progressive gastronomic diversity which survives, unscathed, through the passage of time.

While commenting on the work by Dioscorides of Anazarbo, the Portuguese medical doctor Amatus Lusitanus consigns some contributions related to this issue. The current essay aims to explore it and illustrate it with actual examples taken from the final entries of Book II of In Dioscoridis Anazarbei De Materia Medica Libros Quinque Enarrationes Eruditissimae, printed in 1553, in which there is even some reference to the new products that were then brought to Lisbon, capital of the kingdom, from the distant Madeira Island.

Keywords: Amatus Lusitanus; food heritage; gastronomic diversity; Roman civilization; Discoveries; Madeira Island.

\section{INTRODUÇÃo}

Quando um frio entardecer de Outono nos brinda com o aroma, familiar e reconfortante, de castanhas assadas, acompanhado do pregão "quentes e boas!", ou uma manhã de Primavera nos lembra, com a suave fragrância de cerejas acabadas de colher, que o Verão se aproxima, vem-nos invariavelmente ao pensamento que os ciclos da natureza se renovam, que cada estação nos presenteia com os seus dons e que terá sido assim desde sempre. Presos ao momento histórico em que nos é dado existir, jamais nos ocorre pensar que possa ter havido um tempo em que a realidade tenha sido diferente. Não, obviamente, que os ciclos da natureza alguma vez se tenham suspendido, mas que não tenham sido sempre acompanhados, por exemplo, de castanhas e de cerejas. Tal é, não obstante, a realidade dos factos.

Se nós olharmos os dons da natureza que ornamentam as nossas mesas, nomeadamente os vegetais, se evocarmos o período histórico em que eles foram introduzidos nas nossas dietas e se formos retrocedendo mentalmente no tempo, descobriremos, não sem alguma perplexidade, que as nossas mesas se vão desguarnecendo até ficarem praticamente vazias. Como se sabe, uma mesa bem guarnecida é o espelho de uma civilização, o resultado de um percurso histórico em que cada povo, cada era deixou impressas as suas marcas.

Ora a lição da História costuma ensinar-nos, desde a mais tenra idade, que o território que, de há séculos a esta parte, corresponde a Portugal continental (Algarve de aquém-mar incluído) foi sendo sucessivamente abordado por povos que o demandaram fosse com fins comerciais, fosse com fins de ocupação permanente e integração numa unidade política mais vasta.

Sabe-se, deste modo, que Gregos e Fenícios precederam os Romanos; que estes, principiando no desembarque de Gneu Cornélio Cipião em Ampúrias, no decurso dos anos negros da Segunda Guerra Púnica, iniciaram um processo de conquista e pacificação que se arrastou por cerca de duzentos anos e 
culminou na plena integração da Hispânia no orbis Romanus; sabe-se que esta parte do Império do Ocidente soçobrou ante o avanço de hordas germânicas (Suevos, Vândalos, Alanos e Visigodos) as quais, estabilizadas sob a forma de duas monarquias (a sueva e a visigótica) eventualmente unificadas sob a égide dos monarcas toledanos, sucumbiram à razia muçulmana do séc. VIII; sabe-se, por fim, que das lutas pela libertação do jugo agareno, arrastadas ao longo de oito penosos séculos, emergiram os reinos que estão na origem dos modernos estados-nação de Espanha e de Portugal.

\section{A romanização do Ocidente peninsular}

A romanização da faixa ocidental da Península Ibérica, como é sabido, exerceu-se profundamente nos mais variados âmbitos, mas quando se evoca a herança de Roma pensa-se normalmente na língua e na literatura latinas, no Direito Romano, em pontes, aquedutos, templos e uillae pavimentadas com mosaicos de cores variegadas. Não nos lembramos de Roma quando sentimos o cheiro de castanhas assadas ou de cerejas acabadas de colher e, no entanto, deveríamos com justiça fazê-lo, pois estas espécies (ou, pelo menos, as variedades que hoje utilizamos na alimentação) terão sido introduzidas pelos Romanos.

A acção deste povo, em termos civilizacionais, tendeu a uniformizar a paisagem mediterrânica, através da difusão de um grande número de espécies vegetais que nos são extremamente familiares. A título meramente ilustrativo e sem a intenção de explorar esta questão em profundidade, o que assumidamente não corresponde aos objectivos deste ensaio, lembremos apenas que: "Os Romanos terão introduzido novas variedades de espécies e novas técnicas de cultivo, que tornaram a actividade agrícola mais rendível” ${ }^{1}$. Esta difusão seguiu, em geral (mas não exclusivamente, como adiante veremos), uma rota orientada de Leste para Oeste ${ }^{2}$. Afirma categoricamente Plínio, o Naturalista, que: Não houve cerejeiras em Itália antes da vitória de Lúcio Lúculo sobre Mitridates, até ao ano 680 da [fundação da] cidades. Ele trouxe-as primeiramente do Ponto e, em 120 anos, chegaram mesmo, além do oceano, à Grã$B r e t a n h a^{4}$. Na Península Itálica teria havido, até ao séc. I a. C., apenas uma variedade selvagem de cerejeira, não a que nos é hoje familiar. Pessegueiros e damasqueiros, oriundos estes do Turquestão, aqueles da longínqua China, trazidos pela Rota da Seda e através da Ásia Menor, chegaram a Itália no

${ }^{1}$ Centeno 1983: 182.

${ }^{2}$ Braudel 2001: 326.

${ }^{3} \mathrm{Ou}$ seja, no ano 73 a. C.

${ }^{4}$ Cerasi ante uictoriam Mitbridaticam L. Luculli non fuere in Italia, ad urbis annum DCLXXX. Is primum uexit e Ponto, annis CXX trans oceanum in Brittanniam usque peruenere, Plin. Nat. 15.102. 
século I d. C. Do Oriente tinham vindo nogueiras e amendoeiras; de Creta vieram os marmeleiros; da Ásia Menor os castanheiros, cujo fruto encontramos já à rústica mesa de Títiro, pastor da Écloga I de Virgílio ${ }^{5}$. E, no entanto, este fruto era ainda desconhecido de Catão, o Censor (234-149 a. C.) ${ }^{6}$.

Antes da introdução destas espécies, já a oliveira, os cereais (como o trigo, a cevada, a aveia e o centeio) e a vinha tinham iniciado, por mãos de Gregos e de Fenícios, o seu processo de difusão, que os Romanos completaram. A oliveira era natural da Península Arábica e da Ásia Menor; a vinha, com toda a probabilidade, da Transcaucásia. O cultivo de umas e de outras disseminou-se pelos campos de Itália, depois da Península Ibérica e da Gália, tendo o seu cultivo sido tentado até em Inglaterra. "O óleo, o vinho, os cereais, os legumes secos" escreve Braudel "eis já tudo isto ou quase, na mesa quotidiana dos homens do Mediterrâneo"7.

No caso do Portugal romano, as culturas mais relevantes terão sido, além da cerealífera, as da oliveira e da videira: "A oliveira e a videira eram cultivadas a norte e a sul do Tejo. Estrabão refere ricos olivais e vinhas na região de Moron (perto de Santarém) e Políbio informa-nos que o vinho da Lusitânia meridional tinha um preço muito baixo"s. Haveria certamente outras árvores frutíferas, embora as fontes antigas, como Plínio, o Naturalista, apenas mencionem cerejeiras (muito provavelmente uma variedade indígena) e figueiras. Cultivados eram ainda os espargos, as favas, as ervilhas e, em certas regiões do Norte, o centeio e o milho-miúdo.

\section{O domínio islâmico da Península Ibérica}

Se o período da dominação romana assistiu à difusão de tantas espécies que tendemos agora a considerar como genuinamente portuguesas, o ciclo que se abre após o desastroso ano de 711 não terá sido tão pródigo na introdução de novas culturas. As novidades iriam ser de outra índole. Oriunda dos territórios desérticos do sul da Península Arábica, onde a água, sempre escassa, permitia, não obstante, o desenvolvimento de uma actividade agrí-

${ }^{5}$ Cf. Verg. Ecl. 1. 79-82: Hic tamen mecum poteras requiescere noctem/ Fronde super uiridi; sunt nobis mitia poma,/Castaneae molles et pressi copia lactis.

${ }^{6}$ Se retrocedermos no tempo a um período anterior ao domínio romano da Península Ibérica, não serão apenas as nossas mesas que ficam vazias, sendo que acabamos mesmo por ficar praticamente sem mobília. Efectivamente, entre as madeiras nacionais mais utilizadas na marcenaria artística portuguesa, pelo menos desde o séc. XVIII, constam precisamente a cerejeira, a nogueira e o castanho, todas elas introduzidas no período da dominação romana. No caso particular desta última madeira, a sua existência em grande abundância propiciou, no séc. XVII, o desenvolvimento da talha dourada, uma das mais características formas de expressão artística portuguesa.

${ }^{7}$ Braudel 2001: 327.

${ }^{8}$ Centeno 1983: 183. 
cola justificativa do cognome de Arabia felix (a Arábia fértil), a civilização islâmica soube tirar partido dos recursos hídricos existentes nos territórios onde veio a instalar-se.

Tendo aproveitado dos conhecimentos e técnicas deixados pelos antigos Romanos, desenvolveram os Árabes as culturas de sequeiro e de regadio. O que é mais, fixando-se nas bacias de rios como o Tejo ou o Guadiana, entre outros, introduziram o sistema de irrigação elevatória que operava por via de engenhos agora de todos conhecidos, tais como a nora e a azenha. Permitiam estes engenhos elevar a água dos caudais, canalizando-a, depois, para uma rede de levadas que a transportava a distâncias consideráveis. Pôde a área das explorações agrícolas ser, deste modo, significativamente alargada, o que teve reflexos na quantidade e na qualidade da produção.

Entre as espécies introduzidas ou divulgadas pelos árabes (e, de novo, a título meramente exemplificativo), contam-se citrinos como o limão e a laranja azeda (a que poderá acrescentar-se talvez uma variedade doce), cereais como o trigo mourisco e o arroz e ainda uma especiaria como o açafrão. Algumas culturas já existentes foram grandemente desenvolvidas, em especial na região sul, como é o caso da alfarrobeira, da figueira e da amendoeira ${ }^{9}$. A vitivinicultura, herdada dos Romanos, foi então menos praticada, porque condicionada pela interdição corânica.

E que dizer das já então seculares oliveiras? O incremento da sua cultura foi tal que o seu fruto, a que os Romanos chamavam oliva, tomou o nome árabe de "azeitona" e o produto que dele se extrai, em tempos chamado oleum ou oliuum, passou a chamar-se "azeite"10. A par com a fruticultura, este produto, indispensável na cozinha, mas então também para efeitos de iluminação e higiene, sustentava a vida urbana e o comércio, que se operava, nesta economia de base essencialmente agrária, por via da troca de excedentes $^{11}$. Note-se que a substituição do velho nome de origem latina por um de origem árabe afectou ainda outros produtos agrícolas, como, por exemplo, a alface e a cenoura ${ }^{12}$.

Heranças deste período ficaram, além dos produtos acima indicados, os engenhos de irrigação elevatória, com expressão visível ainda nos nossos dias, e as levadas que, na Ilha da Madeira, vieram a assumir um inaudito protagonismo. Se dúvidas houvesse quanto à filiação destas, bastaria compará-las com as suas congéneres nas colinas da Alhambra e do Generalife, em Granada.

\footnotetext{
${ }^{9}$ Araújo 1983: 264-265.

${ }^{10}$ Machado 2003: 1. 361; 1991: 80.

${ }^{11}$ Araújo 1983: 265.

${ }^{12}$ Machado 2003: 1. 198; 2. 114; 1991: 52.
} 


\section{A Expansão portuguesa}

O fim do domínio islâmico na Península Ibérica, com a conquista do reino de Granada em 1492, coincide cronologicamente com o que se pode considerar o início de um terceiro grande ciclo de diversificação da gastronomia para os habitantes da faixa ocidental da Península Ibérica: nesse ano, a viagem exploratória de Cristóvão Colombo atingiu as costas das Américas. Alguns anos antes, Bartolomeu Perestrelo conseguira ultrapassar o desde então chamado Cabo da Boa Esperança, numa tentativa de encontrar uma rota alternativa que fizesse desviar para Lisboa o comércio das especiarias.

A questão é apresentada por Niall Ferguson nos seguintes termos:

As especiarias em causa eram a canela, o cravinho, o macis e a noz-moscada. Os Europeus não as conseguiam cultivar mas desejavam-nas para condimentar a comida. Há séculos que a rota das especiarias seguia pelo oceano Índico e subia o Mar Vermelho ou, por terra, atravessava a Arábia e a Anatólia. Em meados do século $\mathrm{XV}$, a sua última etapa - muito lucrativa - era controlada pelos Turcos e pelos Venezianos. Os Portugueses compreenderam que, se conseguissem descobrir uma rota alternativa, descendo a costa ocidental de África, dobrando o Cabo da Boa Esperança e chegando ao oceano Índico, poderiam tomar conta do negócio. ${ }^{13}$

A armada de Vasco da Gama, quatro embarcações com uma guarnição de 170 homens, zarpou de Lisboa a 8 de Julho de 1498 e atingiu Melinde em Fevereiro do ano seguinte. Ficavam assim abertas as portas do Oriente. As do Ocidente, por outro lado, abriram-se oficialmente para Portugal, como é sabido, com o descobrimento do Brasil, em 1500, por Pedro Álvares Cabral.

\subsection{As palavras de Sá de Miranda}

Ao nível da diversidade gastronómica, os Descobrimentos deixaram uma marca indelével cujo rasto perdura até ao presente. As especiarias mais variadas, disponíveis em grande abundância a partir de então, condimentaram a cozinha portuguesa com uma intensidade tal que, no dizer dos contemporâneos, os alimentos se tornavam quase intragáveis.

É pelo menos isto que se depreende dos versos de Francisco de Sá de Miranda que, assumindo-se como um defensor dos bons velhos tempos, qual Catão português, na carta 139, dirigida "A António Pereira, Senhor de Basto, quando se partiu para a corte co'a casa toda", declara: "Tereis em troca manjares,/ Composições delicadas,/ uas por outras grosadas,/ Pelos tempestuosos mares/ A grão perigo buscadas.// [...] Disto o cheiro, disto a

\footnotetext{
${ }^{13}$ Fergusson 2012: 39.
} 
cor,/ Que preço não tem igual:/ Milagres de Portugal:/ - Cousas de tanto sabor/ Para saberem tão mal!" ${ }^{14}$.

Já as antigas ceias da aldeia, com a sua comida de sabor não adulterado, são, por contraste, objecto de nostálgica evocação: "A vossa fonte tão fria/ Da Barroca, em Julho e Agosto,/ Inda me é presente o gosto!/ Quão bem que nos i sabia/ Quanto na mesa era posto!// Ali não mordia a graça,/ Eram iguais os juízes./ Não vinha nada da praça:/ Ali da vossa cachaça,/ Ali das vossas perdizes.// Ali das frutas da terra/ (Que tem cada mês a sua)/ Colhida em sazão cada ua,/ Nunca o sabor à cor erra,/ Nem ao nome de nenhua"15. Que frutas teria Sá de Miranda em mente nesta quintilha? Acaso as antigas frutas naturais do reino, tais como maçãs e peras, mas também pêssegos, damascos, uvas e cerejas?

Lembremos que, abertas as portas de outros mundos, guarneceram-se paulatinamente as mesas do Ocidente peninsular com batatas, pimentões, inhame, beringelas, tomates, maracujás, ananases, bananas, nêsperas, abacates, papaias, mangos e tantas, tantas outras iguarias. O seu estudo aprofundado e exaustivo, repita-se, não é comensurável com a dimensão do presente ensaio.

\section{As Enarrationes Eruditissimae de Amato Lusitano}

Se considerarmos a obra de Amato Lusitano, médico português contemporâneo do ciclo dos Descobrimentos, não deixaremos de encontrar alguns indícios daquilo a que poderemos talvez chamar uma "consciência" desta progressiva diversificação gastronómica como resultado da dinâmica civilizacional descrita.

Tomemos como amostra um excerto do Livro II das Enarrationes Eruditissimae. Esta obra foi publicada sob título completo de In Dioscoridis Anazarbei de Medica Materia Libros Quinque Enarrationes Eruditissimae (ou seja Os Muito Eruditos Comentários aos Cinco Livros do De Medica Materia de Dioscórides de Anazarbo ${ }^{16}$ ). O próprio rosto da edição afirma tratar-se de uma obra capaz de trazer proveito não só aos comerciantes de fármacos, mas também àqueles que se dedicam ao estudo das belas-letras (ou, no original, non solum officinarum seplasiariis, sed bonarum etiam litterarum studiosis).

O excerto compreende apenas 36 comentários (enarrationes 99 a 135) de um livro que totaliza 183, sendo a obra constituída por cinco livros. Neste segmento, Amato Lusitano ocupa-se apenas de espécies plantas, muitas das

${ }^{14}$ Miranda 1977: 15, 17.

${ }^{15}$ Idem, ibidem: 25-27.

${ }^{16}$ A tradução portuguesa deste título e dos outros trechos da obra de Amato Lusitano transcritos neste ensaio foi realizada pelo autor do mesmo no âmbito do projecto de I\&D "Dioscórides e o Humanismo Português: os Comentários de Amato Lusitano", (Projecto FCT - PDTC/CLE - LLI/101238/2008). 
quais guarnecem ainda hoje as nossas mesas. Sobre a identificação de algumas e, em especial, de certas variedades deve, por enquanto, dizer-se que non liquet.

\subsection{Aportações romanas}

\subsubsection{A cherívia}

No comentário 108, consagrado à cherívia, planta ainda hoje comum nas regiões interiores de Portugal em que o solo gela durante o Inverno ${ }^{17}$, Amato Lusitano escreve:

[...] cuius radices apud Hispanos Lusitanosque in victu frequentes sunt, quas Graeca voce depravata, suo idiomate, "chirivias" appellant.

[...] Ceterum adeo gustui gratae radices istae sunt ut olim Tiberius Caesar (ut narrat Plinius) eas singulis annis, e Germania Romam, pro suo victu afferre curaverit. ${ }^{18}$

\section{Ou seja,}

As suas raízes, entre os Espanhóis e os Portugueses, são frequentes na alimentação. Designam-nas, no seu idioma, por meio de uma palavra grega corrompida: "cherívias".

[...] De resto, são essas raízes por tal forma agradáveis ao paladar que outrora Tibério César (como refere Plínio) as mandou trazer em cada ano, da Germânia para Roma, para sua alimentação ${ }^{19}$.

A importação de cherívias nórdicas para solo itálico pelos Romanos pode depreender-se destas palavras, não sendo todavia claro que as da Península Ibérica tenham a mesma origem nórdica e procedam de difusão operada em tempos romanos.

\subsubsection{A couve dos Sabinos}

Não é esse o caso de uma variedade de couve referida no comentário 114. Nesta enarratio escreve Amato Lusitano que:

[...] cuius plures et variae sunt species, quas Dioscorides, ut hortis et culinae familiares, silentio praeteriuit. Plinius tamen verbosius eas prosequitur, libro decimo nono, capite octavo, ubi sabellicam maxime laudat, quam quoque hodie in

${ }^{17}$ Desta circunstância parece ter-se apercebido Plínio, o Naturalista, visto observar: Gelduba appellatur castellum Rheno inpositum, ubi generositas praecipua, ex quo apparet frigidis locis conuenire, Plin. Nat. 19.90.

${ }_{18}$ Amatus Lusitanus 1553: 237.

${ }^{19} \mathrm{Cf}$. Siser et ipsum Tiberius princeps nobilitauit flagitans omnibus annis e Germania, Plin. Nat. 19. 90 . 
honore universa Italia habet, admiranda foliorum crispitudine, et eam "caulem florem" appellat.

Primo ex Syria advectam, iam nunc in Flandriam et alias exteras nationes transportatam, advehitur namque, ut dixi, semen istius brassicae ex Syria, quod primo anno satum ex se praedictam emittit brassicam, ex qua postea semen ortum ac satum non quidem brassicam gignit, sed potius in rapam degenerat; quod advertens Plinius dixit, libro decimo nono, capite decimo, ex semine brassicae veteris rapae fiunt. ${ }^{20}$

Ou seja,

São bastante numerosas e variadas as suas espécies, as quais Dioscórides, por serem mais comuns nas hortas e nas cozinhas, passou em silêncio. Plínio, contudo, descreve-as mais prolixamente, no livro décimo nono, no capítulo oitavo, onde concede os maiores louvores às dos Sabinos, que também hoje a Itália inteira tem em consideração, pelo admirável frisado das suas folhas, e chamam-lhe couve-flor. Foi ela trazida primeiramente da Síria, agora levada já para a Flandres e outras nações estrangeiras. É, com efeito, trazida da Síria, como já disse, a semente dessa couve que, semeada, faz brotar de si, no primeiro ano, a couve anteriormente referida; depois, a semente dela nascida e plantada não produz contudo uma couve, mas antes degenera em rábano. Plínio, chamando a atenção para este facto, disse, no livro décimo nono, capítulo décimo, que da semente da couve velha surgem os rábanos ${ }^{21}$.

A difusão desta espécie terá sido, pois, iniciada pelos Romanos.

\subsection{Aportações islâmicas}

\subsubsection{O espinafre}

As entradas em apreço são francamente escassas no que respeita à introdução e difusão de espécies pela civilização islâmica. Um indício, porém, encontra-se no comentário 109, consagrado ao espinafre, quando Amato procura explicar a origem do seu nome: spinachia dicta, quia ex Hispania forte primo allata in alteras regiones fuerit aut, ut ego credo, quia semen spinosum habeat ${ }^{22}$, ou seja, é chamado espinafre porque talvez tenha sido primeiramente levado de Espanha para outras regiões ou, segundo estou em crer, por ter uma semente coberta de espinhos.

Ao nome português deste legume (espinafre) atribui o etimologista José Pedro Machado origem persa, por via do árabe, afirmando que "a planta é,

\footnotetext{
${ }^{20}$ Amatus Lusitanus 1553: 240.

${ }^{21} \mathrm{Cf}$. Namque et ocimum senectute degenerat in serpullum, et sisymbrium in zmintham, et ex semine brassicae uetere rapa fiunt, atque inuicem, Plin. Nat. 19. 176.

${ }^{22}$ Amatus Lusitanus 1553: 238.
} 
realmente, originária do Oriente mediterrânico: creio, no entanto, na influência do radical espin-, de espinha, espinho, etc." ${ }^{23}$. A referência de Amato Lusitano a Espanha permite de algum modo suspeitar que este considerasse que a introdução e difusão do espinafre teria sido iniciada em tempos de domínio muçulmano.

\subsubsection{A nomenclatura islâmica}

Inequivocamente de origem árabe é, como já vimos, o nome dado em português à alface e tal peculiaridade patenteia-se no título da enarratio 130 quando é apresentado o nome deste legume em várias línguas: Graece,

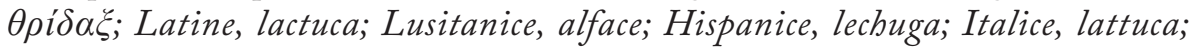
Gallice, une lactue; Germanice, lattich ${ }^{24}$, ou seja, em grego, $\theta \rho i \delta \alpha \xi$; em latim, lactuca; em Português, alface; em língua da Hispânia, lechuga; em língua da Itália, lattuca; francês, une lactue; em língua da Germânia, lattich. O seu étimo latino é explicitado por Amato nos seguintes termos: Dicitur lactuca, ut Palladio in Ianuario placet, quod abundantia lactis exsuperet, ou seja, Chama-se lactuca, como é do agrado de Paládio, em Janeiro, porque se distingue pela abundância de leite. Embora as nomenclaturas sejam, com toda a probabilidade, obra dos editores, Amato Lusitano não podia deixar de ter conhecimento quer da diferença etimológica existente entre o português e as outras línguas suas conhecidas, quer da origem arábica deste vocábulo, quer ainda dos factos civilizacionais que o explicavam.

\subsection{Aportações de novos mundos: $O$ inhame e a batata}

Contrariamente a estes dois últimos exemplos, reconhecidamente menos claros, a enarratio centésima encerra um texto vibrante, espontâneo, em que o parecer das autoridades antigas, ao contrário do que acontece em outras entradas, é praticamente silenciado pelas observações do próprio Amato Lusitano. É este comentário consagrado ao inhame, raiz de uma planta que, em Dioscórides, recebe o nome de fava-do-Egipto. Vale a pena considerá-lo na íntegra:

\section{De Faba Aegyptia}

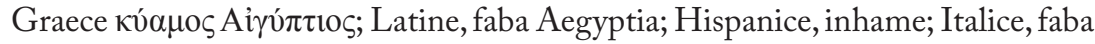
de Egitto.

\section{Enarratio centesimi capitis}

Recte admodum tradit Dioscorides Aegyptiae fabae radicem olim homines comedere, cum hodie sciamus ea multo plures quam tritico aut fruge altera ali. Nam innumeri fere dixerim Aethiopum populi nigritarumque amplissima regio

\footnotetext{
${ }^{23}$ Machado 2003: 2. 465.

${ }^{24}$ Amatus Lusitanus 1553: 253.
} 
hanc radicem in cibo, panis loco, tantum habent, quam sua voce "inhame" vocant. Radicem albam, quam meliorem dicunt, ruffam verum minus bonam, brachialis crassitudinis, magnitudinis vero vulgarium raporum, quam crudam, et sub cineribus coctam, aut aqua elixam, per se vel cum oryza mandunt.

Nec enim in Aethiopia tantum aut Aegypto, ubi "colocasium" appellatur, radix haec invenitur, sed in Lusitania, praecipue apud Salatium, oppidum Setubalum hodie dictum, ubi in lacubus nonnullis perbelle crescit, Dioscoridis historiae in universum respondens. Nec minus Venetiis faba haec Aegyptia in nonnulis amenissimis hortis sata cernitur, folio peramplo, nenupharino aequali, quod Ioannes Falconerius Anglus, vir doctus et simplicium medicamentorum diligentissimus investigator, mihi et doctissimo Brassavolae tanquam rem raram Ferrariae monstravit.

Nos vero, ut verum dicamus, millies hanc comedimus radicem, et illam quidem sub cineribus coctam, cuius sapor castanearum sapori respondet. Nam alimentum penitus humidum radix haec praebet, non minus ac radices aliae, quae ex insulis Capiviridis afferuntur, "batatae" dictae, quibus quoque populi illi loco panis utuntur, et eas Olyssipponenses frequentissime habent, et in victo pro deliciis sumunt. Praetereo alias plures apud insulam Maderiae nascentes radices, quae inter res nouiter inventas adnumerari debent, de quibus volumen amplum confici possit. ${ }^{25}$

$\mathrm{Ou}$, em versão portuguesa,

\section{Sobre a fava-do-Egipto}

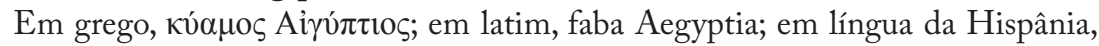
inhame; em língua de Itália, faba de Egitto.

\section{Comentário do capítulo centésimo}

Muito justamente refere Dioscórides que, outrora, os homens se alimentavam da raiz da fava-do-Egipto, já que hoje sabemos que com ela, muito mais do que com trigo ou outro cereal, se alimentam. Com efeito, povos inumeráveis da Etiópia, poderia eu dizer, e uma larguíssima região da negritude em tal abundância utilizam esta raiz na sua alimentação, em lugar do pão. Chamam-lhe, na sua língua, "inhame”. A raiz branca, que dizem ser melhor (de facto, a vermelha é menos boa), tem a grossura de um braço, e o tamanho, em boa verdade, dos nabos vulgares. Comem- na crua e cozinhada sob as cinzas ou cozida na água, sozinha ou com arroz.

E realmente esta raiz não se encontra apenas na Etiópia ou no Egipto, onde é chamada "colocásia”, mas também em Portugal, sobretudo nas proximidades de Alcácer-do-Sal, cidade hoje chamada "Setúbal”, onde em alguns lagos cresce muito belamente, correspondendo, em geral, à história de Dioscórides. E não menos se vê esta fava-do-Egipto em Veneza, plantada em alguns belíssimos hortos, com uma folha muito larga, semelhante à do nenúfar. Apresentou-ma o inglês

\footnotetext{
${ }^{25}$ Idem, ibidem: 228-229.
} 
John Falconer, indivíduo sábio e diligentíssimo investigador dos simples medicinais, a mim e ao doutíssimo Brassávola, em Ferrara, à guisa de coisa rara.

Nós, realmente, para falar verdade, comemos desta raiz milhares de vezes, cozinhada precisamente sob as cinzas e o seu sabor corresponde ao das castanhas. Com efeito, esta raiz proporciona um alimento muito húmido, não menos do que outras raízes que são trazidas das ilhas de Cabo Verde, chamadas "batatas", de que aqueles povos igualmente se servem em lugar do pão, e dela se alimentam com muita frequência os de Lisboa, consumindo-a como uma iguaria. Passo em silêncio muitas outras raízes que nascem na Ilha da Madeira, as quais devem ser incluídas no número das coisas recentemente descobertas, e sobre as quais se poderia escrever um grosso volume.

Abundam, nesta entrada, as referências geográficas explícitas (feitas a Alcácer-do-Sal, a Setúbal, a Lisboa, a Veneza e a Ferrara, à Etiópia e ao Egipto e, especialmente, às Ilhas de Cabo Verde e da Madeira) e Amato não deixa de referir o facto de ter comido inhame milhares de vezes (millies), chegando mesmo a comparar o seu sabor ao das castanhas. Esta enarratio mostra ainda Amato Lusitano em contacto com duas figuras de renome: o inglês John Falconer, mercador e botânico, possuidor de um vasto herbário de plantas secas, e o italiano António Musa Brassávola, professor de medicina em Ferrara.

As palavras finais, por outro lado, além de poderem ser um dos mais antigos testemunhos do consumo de batatas na Europa, são especialmente evocativas do exotismo e novidade que caracterizaram o período iniciado com os Descobrimentos. Amato Lusitano passa em silêncio muitas outras raizes, uma vez que elas, porque recentemente descobertas, não podiam constar na obra de Dioscórides de Anazarbo, de cujo comentário se ocupa neste traba1ho. Note-se, enfim, que essas raízes e outras espécies chegavam à Europa vindas da Ilha da Madeira, do Ocidente, portanto, o que inverteu a direcção geralmente seguida pelas novidades trazidas durante os séculos anteriores.

\section{Conclusão}

Resta, para concluir (e correndo o sério risco de dar a este ensaio um desfecho tautológico), reafirmar que a diversidade gastronómica que guarnece as nossas mesas, especialmente no que respeita a espécies vegetais, resulta de um processo civilizacional desenvolvido ao longo de séculos e por demais conhecido. Que Amato Lusitano não podia deixar de estar, de algum modo, consciente dele esperamos tê-lo demonstrado com os exemplos apresentados.

Uma abordagem mais aprofundada deste tema levar-nos-ia a percorrer as obras de outros autores coevos, em especial os comentadores renascentistas da obra de Dioscórides de Anazarbo e outros naturalistas com obras botânicas próprias. Tal abordagem obrigaria igualmente a percorrer os cinco livros das 
Enarrationes de Amato Lusitano. Explorando a fundo a rica bibliografia existente sobre todos estes assuntos, lendo Amato no seu contexto literário e científico e distinguindo, enfim, entre o que ele apresenta de inovador e o que deve a toda uma tradição prévia permitir-nos-ia determinar em que grau estava ele consciente de que gastronomia e civilização são processos simultâneos. Tal, porém, excede em muito o âmbito deste ensaio e apenas poderá ser desenvolvido em trabalhos futuros.

Ainda assim tenhamos presente que, como reflexo da história de Portugal, a diversidade gastronómica do nosso país constitui-se como um património que, tal como o arquitectónico ou arqueológico, literário ou artístico, etnográfico ou musical, integra, de pleno direito, a nossa herança colectiva.

\section{Bibliografia Final}

Amatus Lusitanus (1553), In Dioscoridis Anazarbei de Medica Materia Libros Quinque Enarrationes Eruditissimae, Venetiis.

Araújo, L. M. (1983), "Os Muçulmanos no Ocidente peninsular", in J. H. Saraiva (coord.), História de Portugal, Volume 1, Publicações Alfa, Lisboa, 245-289.

Braudel, F. (2001), Memórias do Mediterrâneo, Pré-História e Antiguidade, Terramar, Lisboa.

Centeno, R. (1983), “A dominação romana”, in J.H. Saraiva (coord.), História de Portugal, Volume 1, Publicações Alfa, Lisboa, 149-211.

Ferguson, N. (2012), Civilização - O Ocidente es Outros, Civilização, Lisboa.

Machado, J. P. (2003), Dicionário Etimológico da Língua Portuguesa, Volumes 1-5, Livros Horizonte, Lisboa.

Machado, J. P. (1991), Vocabulário Português de Origem Árabe, Editorial Notícias, Lisboa.

Miranda, F. S. (1977), "A António Pereira, Senhor de Basto, quando se partiu para a corte co'a casa toda", in A. P. Torres (ed.), Antologia da Poesia Portuguesa (séc. XII - séc. XX), Volume I, Lello \& Irmão - Editores, Porto, 929-942. 